\title{
Trasplante pulmonar en niños y adolescentes. Experiencia Clínica Las Condes
}

\author{
JOEL MELO T.*, MARÍA T. PARADA C.*, MAURICIO SALINAS F.*, DAVID LAZO P.*, \\ JOSÉ M. CLAVERO R.*, ELI VILLALABEITÍA R.*, PATRICIO RODRÍGUEZ D.*, \\ LORENA CALABRÁN R.* y CRISTINA HERZOG O.*
}

Lung transplantation in children and adolescents. Experience at Clinica Las Condes

Objective: To assess the outcome of patients $\leq 20$ years old subjected to lung transplantation. Methods: Retrospective analysis of clinical records of these patients at Las Condes Clinic, Santiago de Chile. Results: Ten patients $\leq 20$ years old have been subjected to lung transplantation. The median age at transplant was 15.8 years. The main indication was cystic fibrosis in 8 patients. The average baseline $F E V_{1}$ was $31.3 \%$ of its reference value with progressive improvement in FEV $V_{1}$ being 76,3\% after one year and 75,3\% after two years, Early complications were infections and rejection. Late complications were mainly viral infections. Six patients achieved to continue their studies. Survival rate at 30 days, 1 and 5 years were 80, 70 and 58\% respectively. Conclusion: Lung transplantation is an alternative for children and adolescents with advanced lung disease with acceptable results in long-term survival.

Key words: Paediatric lung transplant, Cystic Fibrosis, bronchiolitis obliterans syndrome.

\section{Resumen}

Sólo 45 centros en el mundo desarrollan trasplantes pulmonares en niños. Objetivo: Evaluar resultados de pacientes $\leq 20$ años trasplantados de pulmón. Material y Método: Análisis retrospectivo de registros clínicos de estos pacientes en Clínica Las Condes. Resultados: Diez pacientes $\leq 20$ años han sido trasplantados de pulmón. La edad promedio al momento del trasplante fue de 15,8 años. La principal indicación fue fibrosis quística en 8 pacientes. El VEF $F_{1}$ promedio basal fue de 31,3\% de su valor de referencia, con mejoría progresiva post-trasplante siendo al año de 76,7\% y a los 2 años de $75 \%$, Complicaciones precoces fueron infecciones y rechazo. Complicaciones tardias fueron principalmente infecciones de origen viral. Seis pacientes lograron continuar sus estudios. La sobrevida a 30 días, al $1^{\text {er }}$ y $5^{\circ}$ año fue de $80 \%, 70 \%$ y 58\% respectivamente. Conclusión: El trasplante pulmonar es una alternativa válida en niños y adolescentes con enfermedades pulmonares avanzadas con resultados aceptables a largo plazo.

Palabras clave: Trasplante pulmonar pediátrico, fibrosis quística, síndrome de bronquiolitis obliterante.

\section{Introducción}

Según los registros del año 2013 de la Sociedad Internacional de Trasplante de Corazón y Pulmón (ISHLT) sólo 45 centros en el mundo realizan trasplantes pulmonares pediátricos (TP) y la mayoría de éstos se efectúan en población adolescente entre 11 y 17 años ${ }^{1}$.

El TP en niños presenta particularidades en relación al trasplante en adultos: indicaciones diferentes según grupo de edad, mayor susceptibilidad a infecciones en relación a un sistema inmunitario inmaduro y problemas en disponibilidad de donantes adecuados ${ }^{2}$.

A pesar que los resultados del TP pediátrico han mejorado en las últimas décadas, por los avances en la técnica del trasplante, el manejo peri-operatorio, la inmunosupresión (IS), la profilaxis infecciosa, el mejor manejo de complicaciones; la disfunción crónica del injerto,

* Centro de Trasplantes Clínica Las Condes. Las Condes. Región Metropolitana, Chile. 
como en los adultos es la principal limitante en la supervivencia a largo plazo $^{2}$.

Las principales indicaciones actuales de trasplante pulmonar en mayores de 11 años son la fibrosis quística (69\% de los casos) y la hipertensión arterial pulmonar idiopática, con una sobrevida promedio de 5,3 años similar a lo reportado en adultos (Figura 1) 1 .

El Centro de Trasplantes de la Clínica Las Condes es uno de los principales centros en el país con una experiencia de 16 años en trasplante de pulmón. El objetivo de este estudio es evaluar los resultados de pacientes de 20 o menos años de edad trasplantados en este centro.

\section{Material y Métodos}

Se revisaron retrospectivamente los registros clínicos de pacientes $\leq 20$ años trasplantados en la Clínica Las Condes en los últimos 16 años, evaluando: indicación de trasplante y patología de base, complicaciones precoces ( $<$ de 3 meses) y tardías ( $>$ de 3 meses post-trasplante), evolución espirométrica, reinserción escolar y causas de muerte y supervivencia a 30 días, 1,3 y 5 años. Se excluyeron de este análisis pacientes trasplantados de corazón y pulmón.

El protocolo del estudio fue aprobado por el Comité de Ética institucional

La indicación de trasplante se basó en las recomendaciones de la ISHLT publicadas en el año 1998 y revisadas el año $2006^{3,4}$.

Para el cálculo de sobrevida a 30 días, 1,3 y 5 años se utilizó curva de Kaplan-Meier.

La inmunosupresión incluyó terapia de inducción con Basiliximab ${ }^{\circledR}$ y metilprednisolona $\mathrm{y}$ de mantención con prednisona, tacrolimus y micofenolato o azatioprina. Todos los pacientes recibieron profilaxis antiviral con aciclovir (4-6 meses) o valganciclovir (en pacientes IgG negativos para CMV), antihongos por un año con itraconazol y cotrimoxazol forte trisemanal de mantención. Los exámenes realizados en cada control fueron: exámenes generales, niveles de inmunosupresión, Rx tórax (TAC de tórax según evolución), espirometría y carga viral para CMV. El seguimiento fue semanal el primer mes, quincenal hasta el tercer mes, mensual hasta el año y luego cada 2-3 meses o según necesidad.

Todos los episodios de rechazo agudo fueron confirmados por biopsia transbronquial y fueron manejados con bolos de metilprednisolona por 3 días. Se definió "Síndrome de Bronquiolitis Obliterante post TP" (SBO) como la caída progresiva de la función pulmonar desde la mejor espirometría post trasplante habiendo descartado un diagnóstico alternativo como una complicación anatómica, infecciosa, rechazo agudo, enfermedad pulmón nativo recurrente, etc. ${ }^{5}$.

\section{Resultados}

Entre 1999 hasta noviembre de 2015 se han realizado 89 trasplantes pulmonares en la Clínica Las Condes de los cuales 10 pacientes $(11,2 \%)$ han tenido $\leq 20$ años de edad al momento del trasplante. El promedio de edad de los pacientes fue de 15,8 años (rango 12-20 años), seis fueron de género femenino (Tabla 1).

Nueve pacientes recibieron trasplante bipulmonar y uno fue monopulmonar derecho porque la paciente había sido sometida a una neumonectomía izquierda previamente por hemoptisis masiva. Dos pacientes han requerido injerto bipulmonar reducido de donantes adultos, ambos se encontraban en franco deterioro, dependientes

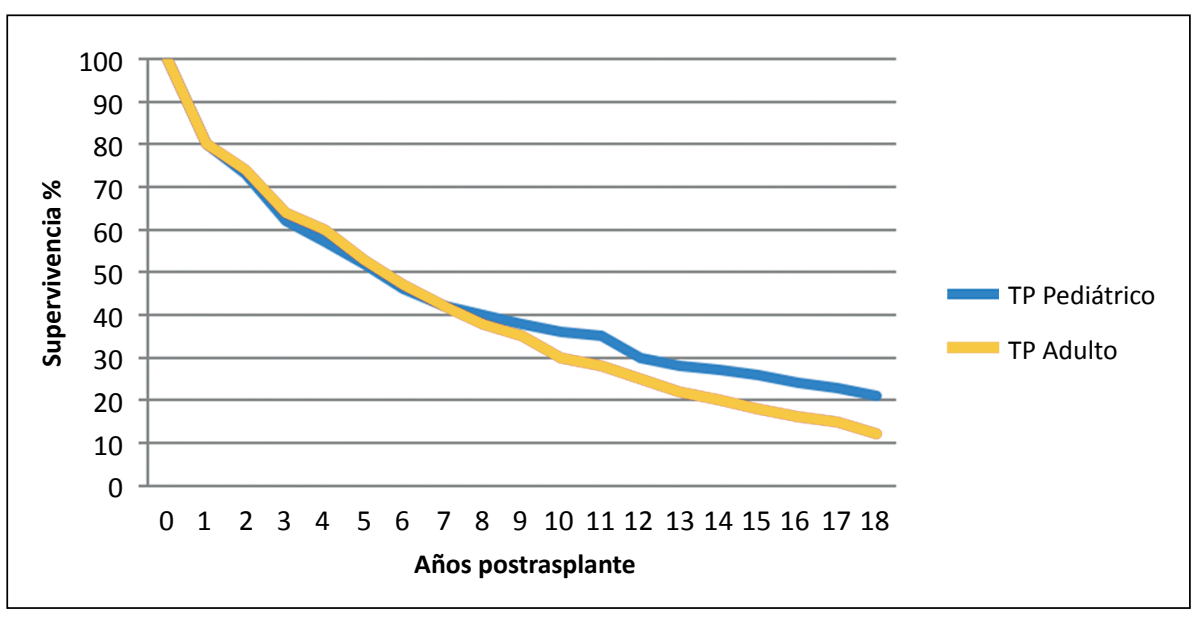

Figura 1. Sobrevida de pacientes con trasplante pulmonar por grupo etáreo: Datos del Registro de la ISHLT 2015. TP: Trasplante pulmonar. ISHLT: Sociedad Internacional Trasplante de Corazón y Pulmón. 
Tabla 1. Características demográficas de 10 pacientes trasplantados pulmonares de 20 o menos años de edad

\begin{tabular}{|ll|}
\hline $\mathrm{n}$ & 10 \\
\hline Edad, años (promedio/rango) & 15,8 (12 a 20) \\
Género (femenino/masculino) & $6 / 4$ \\
\hline $\begin{array}{l}\text { Enfermedad de base } \\
\quad \text { - Fibrosis quística }\end{array}$ & 8 \\
$\quad$ - Bronquiolitis obliterante & 2 \\
Trasplante uni/bipulmonar & $1 / 9$ \\
$\mathrm{VEF}_{1}$ promedio pre-trasplante (\%) & 31,3 \\
$\mathrm{VMNI}^{\mathrm{VMG} C M V ~(+/-) ~}$ & 3 \\
\hline
\end{tabular}

VMI: ventilación mecánica no invasiva; CMV: citomegalovirus: $\mathrm{VEF}_{1}$ expresado en \% de su valor teórico normal de referencia.

de ventilación mecánica no invasiva (VMNI), uno inclusive en urgencia nacional.

La principal indicación de trasplante fue fibrosis quística (FQ) en un $80 \%$ de los pacientes. Tuvimos dos casos de bronquiolitis obliterante: uno secundario a infección por adenovirus en la infancia y otro paciente posterior a un trasplante de médula ósea (TMO) quien desarrolló una patología injerto contra huésped post trasplante. Al momento del trasplante todos eran oxígeno dependientes y 3 requerían de VMNI domiciliaria.

\section{Función pulmonar y reinserción escolar}

Todos los pacientes suspendieron el oxígeno posterior al injerto pulmonar. La función pulmonar pre-trasplante reveló un $\mathrm{VEF}_{1}$ promedio de $950 \mathrm{~mL}$ (rango $480-1760 \mathrm{~mL}$ ) equivalente al $31,3 \%$ de su valor teórico normal (rango 17-
$56 \%$ ) en el seguimiento posterior el $\mathrm{VEF}_{1}$ promedio a los 12 y 24 meses fue de 76,7\%. y $75 \%$ respectivamente (Figura 2 ).

De los pacientes con seguimiento de más de un año, 6 lograron reinserción escolar completa y 5 de ellos completaron estudios universitarios.

\section{Complicaciones precoces}

Complicaciones precoces (menos de 3 meses) se presentaron en 3 pacientes:

Rechazo celular agudo (RCA) en tres de ellos a los 14 y 18 días y 3 meses post trasplante. Un paciente evolucionó con RCA refractario a tratamiento falleciendo por falla orgánica múltiple.

Las complicaciones infecciosas precoces fueron de origen pulmonar, un caso neumonía por Pseudomonas aeruginosa que evolucionó con sepsis falleciendo por esta causa y una bronquitis por Proteus mirabilis resuelta en forma satisfactoria con tratamiento antibiótico. Una paciente con FQ presentó empiema por Burkholderia requiriendo aseo quirúrgico y manejo antibiótico prolongado.

De las complicaciones quirúrgicas la hemorragia con re-exploración fue la más frecuente (40\%). Además, una paciente requirió neumonectomía por trombosis masiva de la vena pulmonar y otro desarrolló precozmente una lesión de sutura con estenosis que requirió de cirugía corrigiéndose en forma completa.

\section{Complicaciones tardías}

El RCA se presentó en tres pacientes, un caso a los quince meses refractario a la terapia, falleciendo. Los otros dos casos presentaron el cuadro de RCA a los 12 meses y otro a los 32 y 48 meses, que fueron resueltos satisfactoriamente.

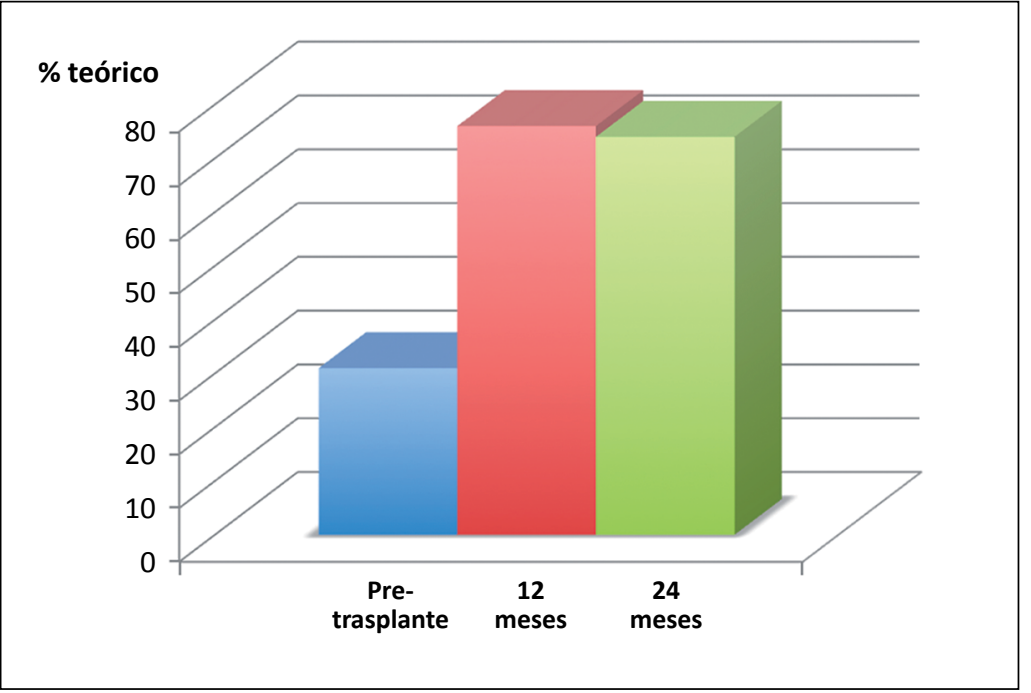

Figura 2. Evolución del $\mathrm{VEF}_{1}$ en $\%$ de su valor de referencia en 10 pacientes con trasplante pulmonar de 20 o menos años de edad. 


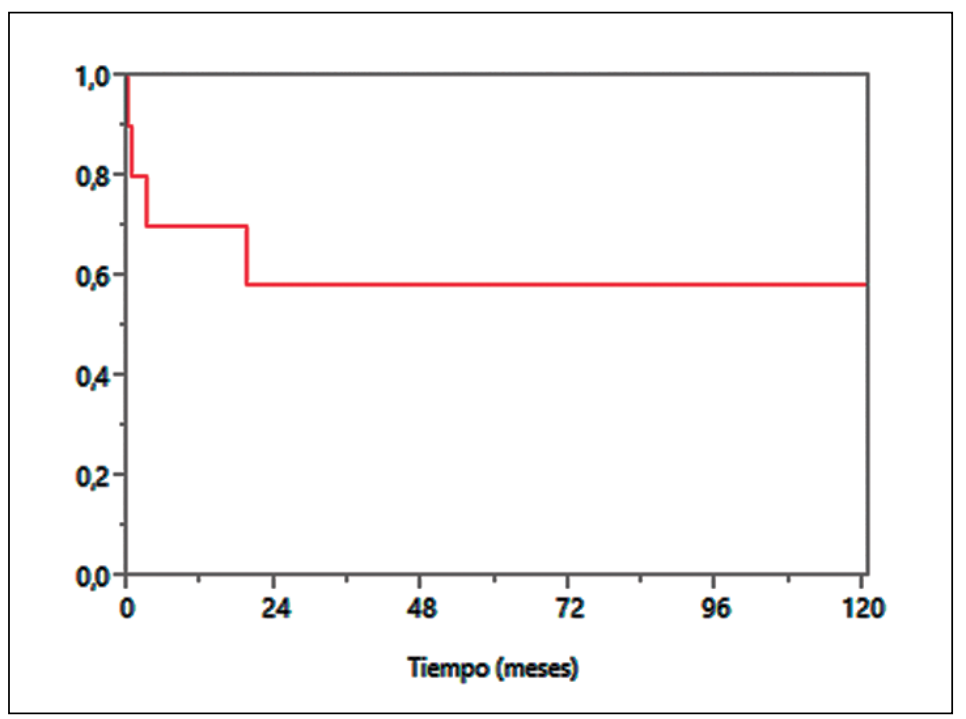

Figura 3. Sobrevida de 10 pacientes trasplantados de pulmón de 20 o menos años de edad (curva de Kaplan-Meier). La supervivencia a 1, 3 y 5 años fue de $70 \%, 58 \%$ y $58 \%$ respectivamente.
En el seguimiento dos pacientes han evolucionado con SBO, uno de ellos falleció a los 11 años de edad.

Complicaciones infecciosas: 8 episodios de sinusitis por Pseudomonas aeruginosa en dos pacientes portadoras de FQ manejadas con tratamiento antibiótico y en conjunto a otorrinolaringología y un paciente con shock séptico por neumococo con recuperación íntegra post tratamiento.

Hemos observado en el largo plazo durante el invierno infecciones por virus comunitarios no complicadas en 5 casos, aislándose: VRS, parainfluenza, bocavirus e influenza AH1N1.

Un paciente portador de FQ presentó al año una tuberculosis pulmonar que fue un hallazgo broncoscópico en la revisión de la sutura y recibió tratamiento completo con evolución satisfactoria.

Sólo una paciente cursó con un Síndrome Linfoproliferativo, diagnosticado a los 11 años post trasplante y que constituyó la causa de su fallecimiento.

\section{Mortalidad}

Seis pacientes han fallecido en el seguimiento. Tres pacientes en los primeros 3 meses; una por hemorragia en el postoperatorio, otra a los 18 días por RCA e infección posterior y uno a los 3 meses postrasplante, por sepsis por Pseudomonas aeruginosa. Una paciente falleció tardíamente a los 15 meses, la que había debutado con un cuadro de hipereosinofilia pulmonar severo con respuesta inicial favorable y fue asociado a probable Aspergillosis pulmonar.
Dos pacientes fallecieron tardíamente a los 10 y 11 años post trasplante por SBO y síndrome linfoproliferativo post trasplante.

El cálculo de sobrevida (Kaplan Meier) a 30 días y a 1, 3 y 5 años fue de 80, 70, 58 y $58 \%$ respectivamente (Figura 3 ).

\section{Discusión}

En nuestro conocimiento, este sería el primer artículo en Chile de pacientes trasplantados pulmonares de 20 o menos años de edad. De los 89 trasplantes pulmonares realizados en nuestro centro, sólo un $11,2 \%(\mathrm{n}=10)$ corresponde a niños y adolescentes $\leq 20$ años. La baja frecuencia de trasplantes en niños y adolescentes es una constante a nivel mundial. En el registro de la ISHLT sólo 124 trasplantes pulmonares pediátricos se realizaron el año 2013, la gran mayoría en pacientes entre 11 y 17 años, comparado con los más de 3.800 trasplantes pulmonares de adultos en el mismo período ${ }^{1}$, esto tiene relación probablemente con una escasa disponibilidad de donantes jóvenes, a una menor prevalencia en niños de enfermedades pulmonares graves terminales y a los avances en el manejo de la FQ que han retrasado la edad en la que estos pacientes pueden requerir un trasplante pulmonar ${ }^{2}$.

En nuestra serie la principal indicación de trasplante fue la FQ (80\%), similar a los datos del registro internacional que muestran que en pacientes trasplantados > 11 años, el $69 \%$ tiene $\mathrm{FQ}^{1}$.

En la mayoría de los niños y adolescentes el trasplante debe ser bipulmonar, procedimiento 
obligado en enfermedades supurativas pulmonares (FQ) y en Hipertensión arterial pulmonar, que son las dos principales causas de trasplante pulmonar en niños ${ }^{2}$. Además, la sobrevida promedio de pacientes pediátricos en que se realiza trasplante monopulmonar es de 2,2 años, significativamente menor que el trasplante bipulmonar que es de 5,6 años ${ }^{1}$. En nuestra serie sólo una paciente se realizó trasplante monopulmonar, era una paciente con FQ con neumonectomía previa, esta paciente falleció a los 11 años de un síndrome linfoproliferativo, habiendo presentado una muy buena calidad de vida previa.

Otro aspecto importante es que debido a su tamaño, los pacientes pediátricos tienen menor posibilidad de obtener un órgano de tamaño compatible requiriendo de otras técnicas quirúrgicas, tales como: trasplante lobar con donante cadáver (Split lung) o desde donante vivo o un bipulmonar con injerto reducido. En nuestra serie, ante la imposibilidad de obtener un órgano adecuado por tamaño, en dos pacientes se ha realizado un trasplante bipulmonar con técnica de injerto reducido. Ambos cursaron con disfunción primaria de injerto de moderada a severa y además por hemorragia post quirúrgica debieron ser re-explorados. A la fecha, ambos pacientes están en buenas condiciones, activos y sin limitación física. Uno cumplió 6 meses y otro 5 años post trasplante.

De las complicaciones precoces destaca la hemorragia con re-exploración en un $40 \%$ de los pacientes. Tiempos operatorios prolongados, uso de soporte extracorpóreo inciden en este mayor riesgo de hemorragia; un paciente que usó ECMO (oxigenador de membrana extracorpóreo) como soporte intraoperatorio falleció por hemorragia.

Las infecciones fueron la principal complicación tardía siendo los virus respiratorios comunitarios (VRC) estacionales los predominantes (VRS, parainfluenza, bocavirus e influenza AH1N1). El retorno a sus actividades cotidianas como estudiantes y la reinserción social predispone a este grupo de pacientes a VRC que afectan a la población general. La evolución en todos estos casos ha sido satisfactoria. En un estudio reciente de pacientes pediátricos trasplantados pulmonares Liu y cols, encontraron una tasa de $14 \%$ de infecciones virales respiratorias (IVR) en el primer año post trasplante y una asociación significativa entre IVR y disminución de sobrevida al año ${ }^{6}$. Si bien Khalifah y cols., concluyen en su estudio que en pacientes trasplantados pulmonares las infecciones virales respiratorias se han asociado a SBO y muerte ${ }^{7}$. Recientemente Liu y cols., en un estudio de 55 pacientes pediátricos trasplantados pulmonares evaluaron el impacto de IVR a largo plazo (seguimiento promedio de 22,2 meses) no encontrando asociación de éstas y el desarrollo de rechazo crónico o mortalidad ${ }^{8}$.

Se describe que los pacientes pediátricos trasplantados presentan un riesgo mayor de neoplasias de tipo síndrome linfoproliferativo relacionado con la infección por el virus de Epstein-Barr con una incidencia que va desde el 4 al $15 \%$ dependiendo del tiempo post trasplante ${ }^{2}$. De nuestros pacientes sólo una paciente desarrolló un linfoma a los 11 años del trasplante.

De 6 pacientes con seguimiento de más de un año el 100\% logró reinserción escolar completa y el $83 \%$ cursó estudios superiores, reflejando que el trasplante pulmonar permite un cambio en su calidad de vida y una franca disminución en las hospitalizaciones tan frecuentes en los pacientes portadores de FQ.

La supervivencia en nuestra serie a 5 años fue de 58\% similar al 54\% y 55\% del registro de la ISHLT y del Registro de Trasplante Español respectivamente. Los lactantes y preescolares parecen tener una mayor supervivencia comparada con la de pacientes mayores de 11 años. Se describe que los adolescentes son menos adherentes a los tratamientos, por lo que en este grupo de pacientes es necesario un seguimiento estricto para mejorar los resultados ${ }^{2}$.

\section{Conclusiones}

El trasplante pulmonar es una opción terapéutica para niños con enfermedad pulmonar terminal con resultados similares a los del trasplante en adultos. La fibrosis quística es la indicación más frecuente de trasplante en adolescentes a nivel nacional e internacional. El TP mejora la sobrevida y la calidad de vida dándole claros beneficios en su reinserción social y laboral.

Entre los desafíos pendientes en nuestro país para este grupo de pacientes es extender la cobertura social y económica que facilite el procedimiento y permitir el acceso a prioridad en las listas de espera.

\section{Bibliografía}

1.- GOLDFARB S, BENDEN C, CHRISTIE J, EDWARS L, KUCHERYAVAYA A, DIPCHAND A, et al. Registry of the International Society for Heart and Lung Transplantation: Eighteenth Official Pediatric Lung and Heart-Lung Transplantation Report 2015. J Heart Lung Transplant 2015; 34: 1255-63.

2.- MORENO A, MONTSERRAT J, ROMAN A. Trasplan- 
te pulmonar en niños. Arch Bronconeumol 2013; 49 : 523-8.

3.- MAURER J R, FROST A E, ESTENNE M, HIGENBOTTAM T, GLANVILLE A R. International guidelines for the selection of lung transplant candidates. The International Society for Heart and Lung Transplantation, the American Thoracic Society, the American Society of Transplant Physicians, the European Respiratory Society. J Heart Lung Transplant 1998; 17 : 703-9.

4.- ORENS J B, ESTENNE M, ARCASOY S, CONTE J V, CORRIS P, EGAN J J, et al; Pulmonary Scientific Council of the International Society for Heart and Lung Transplantation. International guidelines for the selection of lung transplant candidates: 2006 update-a consensus report from the Pulmonary Scientific Council of the International Society for Heart and Lung Transplantation. J Heart Lung Transplant 2006; 25: 745-55.
5.- ESTENNE M, MAURER J R, BOEHLER A, EGAN J J, FROST A, HERTZ M, et al. Bronchiolitis obliterans syndrome 2001: an update of the diagnostic criteria. J Heart Lung Transplant 2002; 21: 297-310.

6.- LIU M, WORLEY S, ARRIGAIN S, AURORA P, BALLMAN M, BOYER D, et al. Respiratory viral infections within one year alter pediatric lung transplant. Trasplant Infect Dis 2009; 11: 304-12.

7.- KHALIFAH A P, HACHEM R R, CHAKINALA M M, SCHECHTMAN K, PATTERSON A, SCHUSTER D. Respiratory viral infections are a distinct risk for bronchiolitis obliterans syndrome and death. Am J Resp Crit Care Med 2004; 170: 181-7.

8.- LIU M, MALLORY G B, SCHECTER, WORLEY S, ARRIGAIN S, ROBERTSON J, et al. Long-term impact of respiratory viral infection after pediatric lung transplantation. Pediatr Transplantation 2010; 14: 431-6.

Correspondencia a:

Dr. Joel Melo T.

Clínica Las Condes

Lo Fontecilla 441

Las Condes, Santiago de Chile.

Email:.jmelo@clinicalascondes.cl 